\title{
MODIFIED FIELD TEST FOR DETERMINING THE SPECIFIC ENDURANCE IN RHYTHMIC GYMNASTICS
}

\section{Maria Gateva}

\author{
National Sports Academy „,Vassil Levski”, Sofia, Bulgaria
}

\begin{abstract}
Several attempts have been made in the past years to create adequate tests in order to determinate the fitness level of the athletes in the gymnastics disciplines. Considering the highintensity movements and the total routine time, we hypostatized that anaerobic metabolism is a determinant for rhythmic gymnastics performance. Based on the physiological indicators of a competitive routine the aim of this study was to create a reliable and valid specific field test to measure the fitness level (specific endurance) of the rhythmic gymnasts competing at national and international level.

12 high level gymnasts aged $15.7 \pm 2.1$ were involved in this study. The testing was done twice - once in the preparatory and second time in the competitive period. Two tests were performed in the field - the specific anaerobic test and a competitive routine. The heart rate and the blood lactate were recorded during and after the load. Specific endurance gymnastics field test is a simple routine including specific but very basic rhythmic gymnastics exercises from each body group - steps; waves; balances; pivots; leaps and acrobatic elements with very low level of difficulties.

The maximal blood lactate concentration levels recorded in both tests and periods did not show any significant difference and varied between 7.2 to $8.4 \mathrm{mmol} / \mathrm{l}$. All of the heart rate values after the loads indicated high work intensity-above $185 \mathrm{bpm}$. There were significant differences in both exercises (specific test \& routine) between the preparatory and the competitive routine. The heart rate clearly showed adaptation of the cardiovascular system towards the load when tapering into the peak performance period. The suggested test is a standard field test suitable for active, mid to high level rhythmic gymnasts aged above 12 years which can measure the current specific endurance of a gymnast and compare it with her previous testing or gymnasts.
\end{abstract}

Key words: rhythmic gymnastics, specific endurance, field test, blood lactate, heart rate

\section{INTRODUCTION}

Several attempts have been made in the past years to create adequate tests in order to determinate the fitness level of the athletes in the gymnastics disciplines. There is a field test in aerobic gymnastics, for example, that measures the anaerobic metabolism performance known also as Borelli's test (Alves et al., 2015). It consists of specific gymnastics elements performed in maximal repeated sprint fashion, during a total timeframe of 80-90 sec which aims at simulating the total duration and intensity of a typical AG competition.

Sleeper et al. (2012) applied a whole battery of tests in order to measure the fitness level in women's artistic gymnastics. There is no doubt that strength, flexibility, mechanical and anaerobic powers are the primary factors in artistic gymnastics performance (Jemni et al., 2011). Some authors (Marina, Rodríguez, 2014), though, suggested that modern female competitive gymnastics imposes higher cardio-respiratory and metabolic demands than previously supposed. 
Several authors have tried to identify the volume of internal load during the competitive program (routine) of rhythmic gymnasts (Gateva, 2014 \& 2015; Fernández-Villarino et al., 2018). A statistical approach highlights the significance of aerobic and anaerobic metabolism (high energy phosphate and glycolysis) for successful performance in rhythmic gymnastics (Douda et al., 2008). The same authors recorded significant (high) correlation between the maximal oxygen consumption and the sport result as continuous maximal exercise for 60 to 90 seconds required aerobic metabolism. In concordance, Guidetti et al. (2000) found that the most taxed energy source during the ball routine was aerobic, which enabled athletes to perform high-intensity rhythmic gymnastics routines and also pointed out the importance of anaerobic metabolism. Training sessions and programs require gymnasts to have endurance in force production in rhythmic gymnastics (Polat, Günay, 2016). The routines have a short duration and the exercise intensity is maximal at some moments (Batista et al., 2018). The load during the competitive routine in rhythmic gymnastics has very high demands on the anaerobic system (Manos, et al., 2012) - blood lactate concentration after a group routine is up to $12.2 \mathrm{mmol} / \mathrm{l}$. Similar and even higher results were obtained with the Bulgarian national team (Nikolov, Katelieva, 2004).

Wingate test is used in artistic and aerobic gymnastics to measure the anaerobic power of the athletes. In rhythmic gymnastics, though, this test is not adequate because it is designed towards more power orientated specific sports. $\mathrm{VO}_{2}$ max is not appropriate either, as it measures the aerobic capacity. Considering the high-intensity movements and the total routine time, we hypostatized that anaerobic metabolism is a determinant for rhythmic gymnastics performance. Based on the physiological indicators of a competitive routine the aim of this study was to create a reliable and valid specific field test to measure the fitness level (specific endurance) of the rhythmic gymnasts competing at national and international level.

\section{METHODS}

\section{Subjects}

12 high level gymnasts (some in the Bulgarian National team) aged $15.7 \pm 2.1$ were involved in this study. The competitors were category "elite" from Levski Triaditsa sports club in Sofia, training 30 to $35 \mathrm{~h}$ per week. The testing was done twice - once in the preparatory period and second time in the competitive period. Two tests were performed in the field - the specific anaerobic test and a competitive routine. Parental permission and informed consent were obtained from all participants.

The collected data were used in two ways - to check the validity of the test compared to other test as well as to determinate the sensibility of the test (comparing the values between preparatory and competitive period to see if the positive changes from tapering in peak performance are determined by the test).

\section{Instruments}

Heart rate was recorded by POLAR RCX3. The recording started at rest and continued until $10 \mathrm{~min}$ post exercise (recovery period). A drop of blood sample was taken from the fingertip to measure blood lactate using an Accutrend Plus Roche. Lactate was taken before and at the $3^{\text {rd }}, 5^{\text {th }}$ and the $9^{\text {th }}$ min during the recovery period.

\section{Study design}

Specific endurance gymnastics field test is a simple routine including specific but very basic rhythmic gymnastics exercises from each body group - steps; waves; balances; pivots; jumps \& leaps and acrobatic elements with very low level of difficulties. We investigated if the load during the test would match the ef- 
fect of performing a real gymnastics routine regarding the HR and blood lactate values from both executions in both periods (preparatory \& competitive).

\section{Warm up}

The test was carried out at the beginning of the training sessions after a 30 min warm up, followed by a 10 min specific warm up prior to each of the two routines. After the completion of the first test the gymnasts were given a passive recovery period for $10 \mathrm{~min}$. The next field test was done after $20 \mathrm{~min}$.

Description of the test (Author test) - specific endurance rhythmic gymnastics field test.

The total duration of the routine is $1.58 \mathrm{~min}$ performed on the standard RG carpet $13 \times 13 \mathrm{~m}$. The presented 21 exercises in table 1 are $59 \mathrm{sec}$ long and in order to perform them in tempo the song ,, We Will Rock You” by Queen was played (84 bpm). The route is repeated twice to reach the target time of $2 \mathrm{~min}$. (1.58 $\mathrm{min})$. It is composed of typical basic exercises for rhythmic gymnastics where the order of the performed elements is based on the choreographic decisions and alternation of the elements from the different body groups. All of the specific exercise groups are displayed in this routine with low level of difficulty and structure close to the competitive one. The aim of the test is to achieve the closest possible dynamics and kinematics of the rhythm in a gymnastics routine.

Table 1. Description of the specific endurance rhythmic gymnastics field test

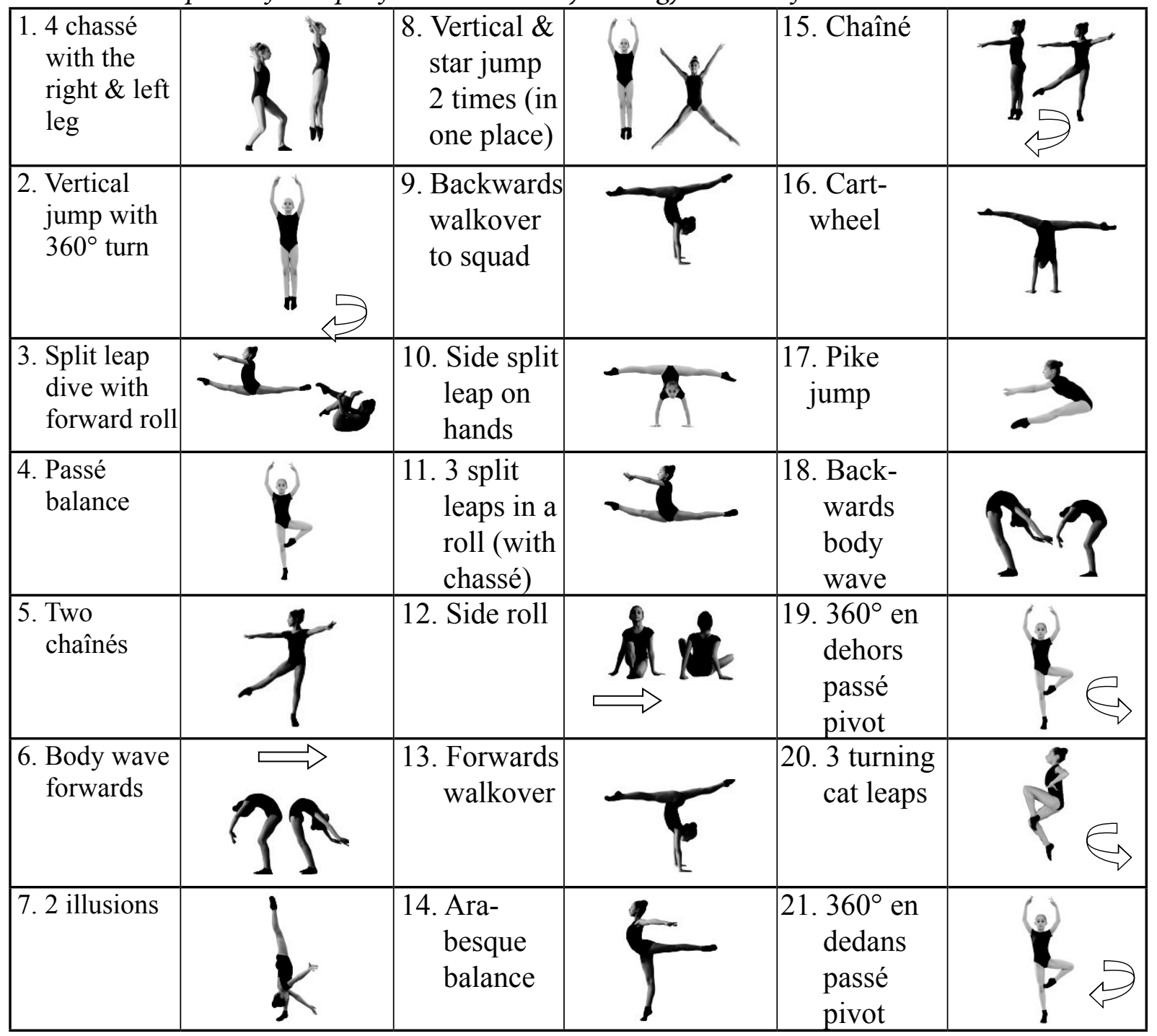




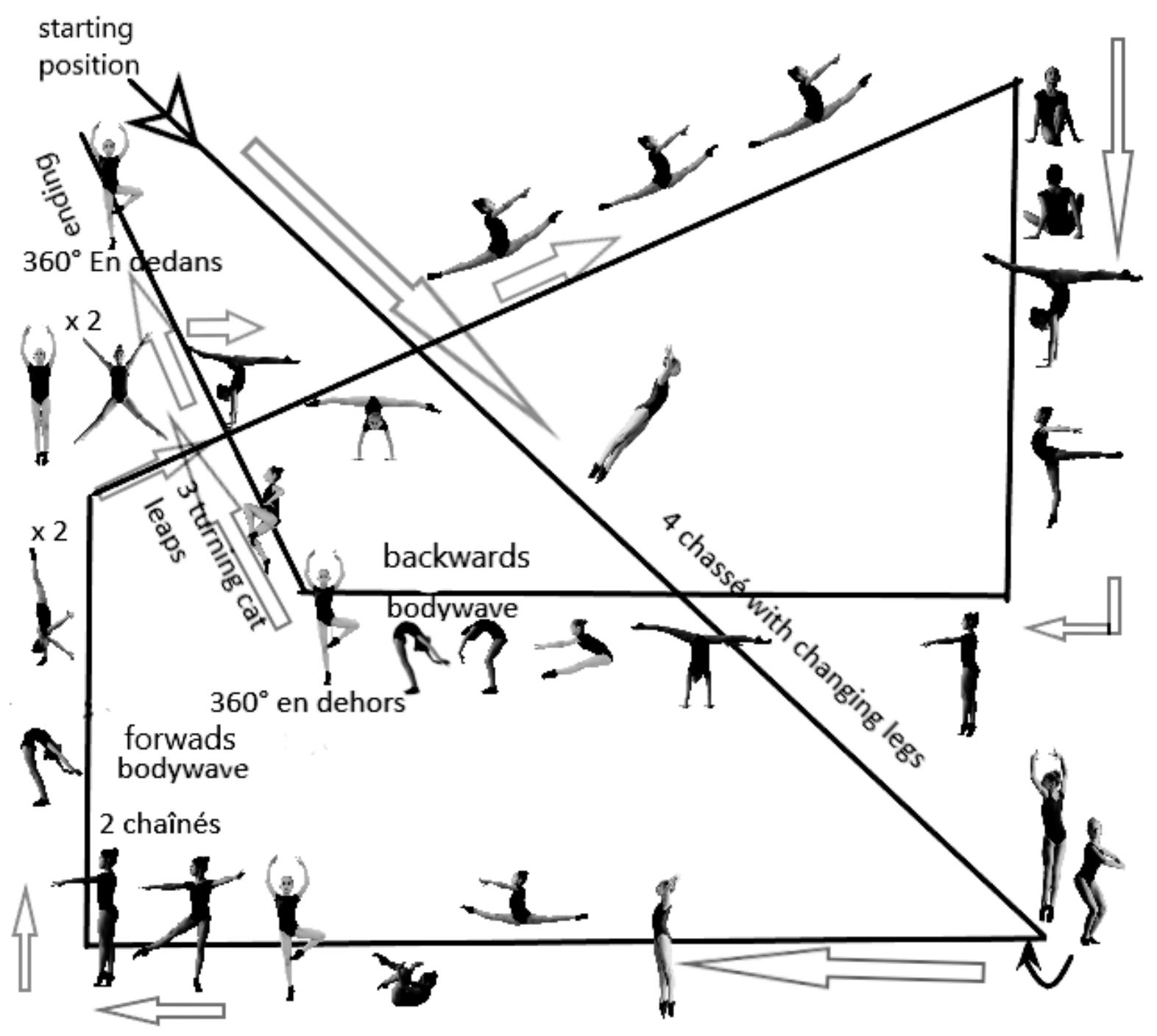

Figure 1. Directions and illustration of the specific endurance rhythmic gymnastics field test

\section{Statistical analysis}

Descriptive statistics was used to characterize the physiological reaction during and after applying the tests and routines in rhythmic gymnastics.

Pearson's correlation coefficient measures the relationship between the competitive routine and our specified field test (routine) based on the heart rate and blood lactate results. Student's paired t-test was applied to find differences in heart rate monitoring and blood lactate measurements between the two periods - preparatory \& competitive period. The level of significance of $p \leq 0.05$ was adopted in all cases.

\section{RESULTS}

The values of heart rate and blood lactate concentration measured during and after the specific endurance test on the field and the competitive gymnastic routines in both periods are summarized in the figures and tables below. The maximal blood lactate concentration levels recorded in both tests and periods did not show any significant difference. 


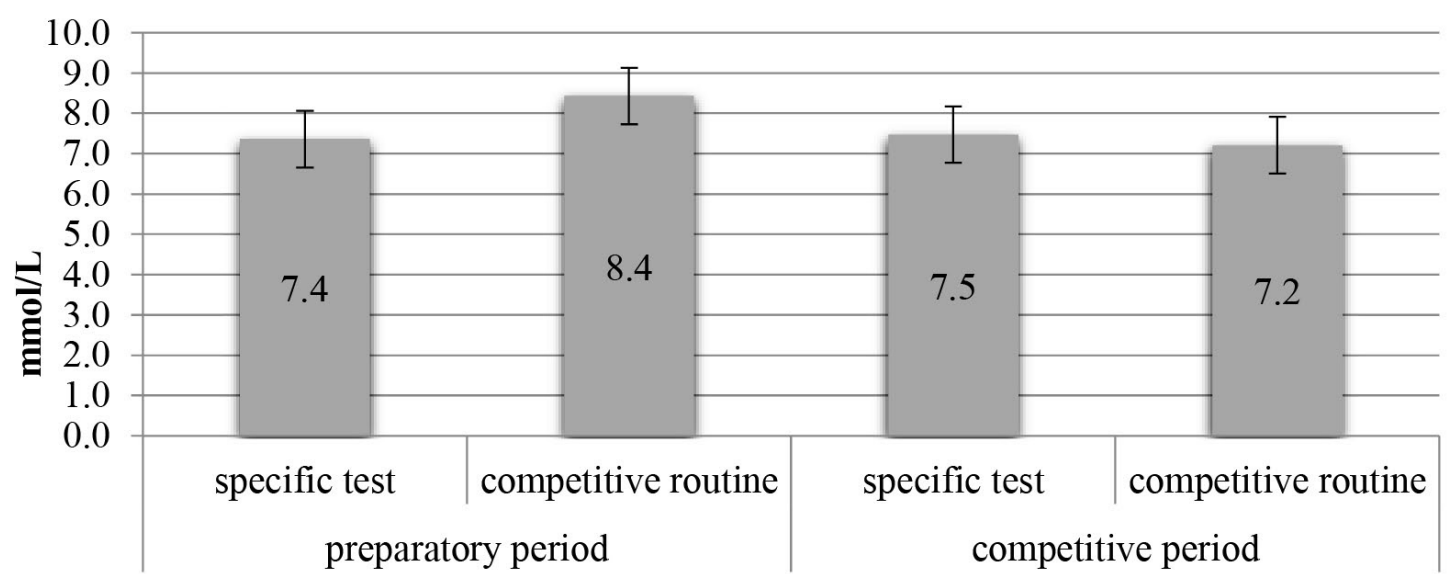

Figure 2. Blood lactate levels after specific test \& routine

A very strong correlation in blood lactate in- between the specific test and the competitive dicator during the competitive period was found routine but not in the preparatory period.

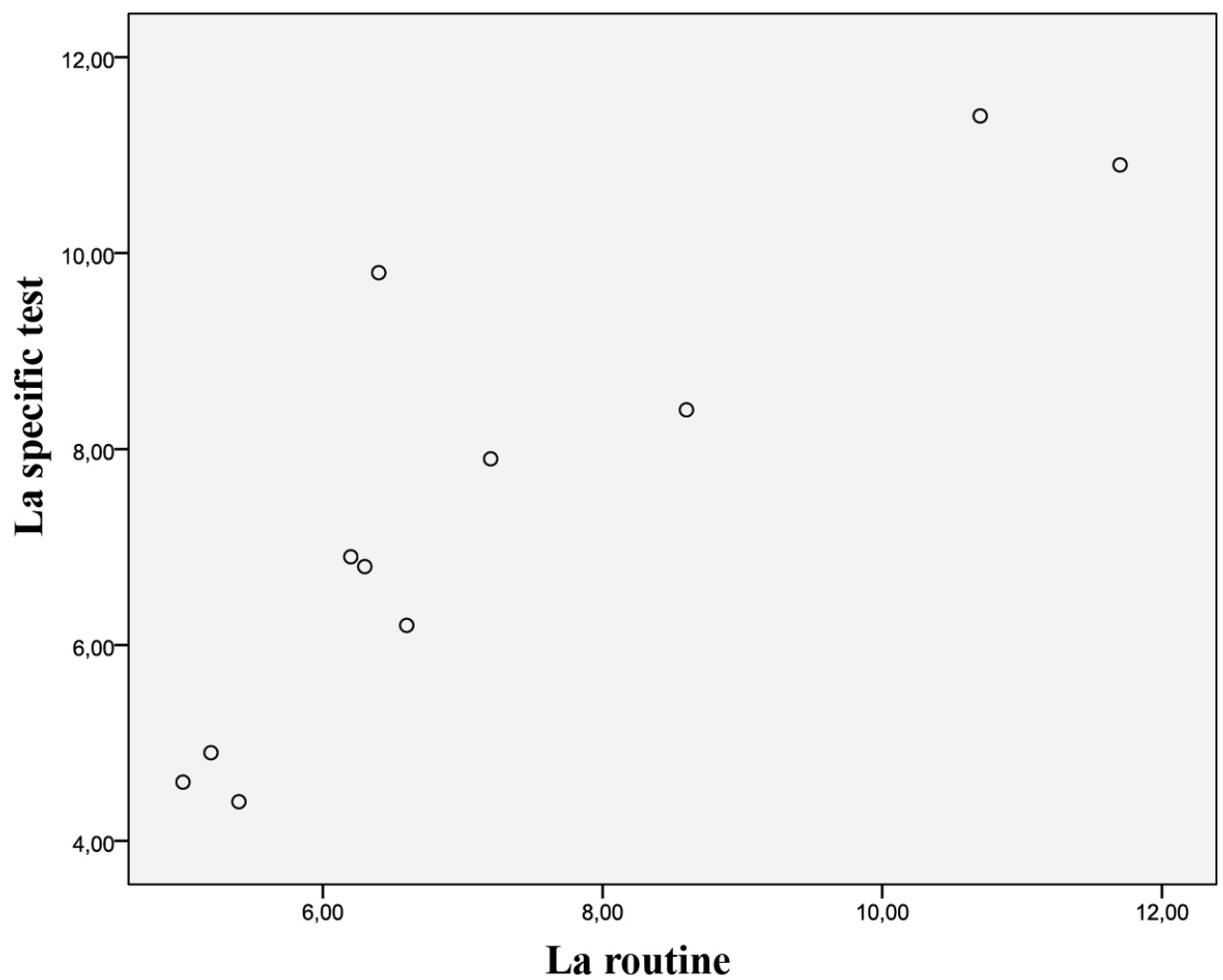

Figure 3. Pearson correlation coefficient-blood lactate concentration in competitive period

Moderate correlation was recorded in the peak heart rate values in both testing - in preparatory and in competitive period. All of the heart rate values after the loads indicated high work intensity - above $185 \mathrm{bpm}$. There were significant differences in both exercises (specific test $\&$ routine) between the preparatory and the competitive routine. The heart rate clearly showed adaptation of the cardiovascular system towards the load when tapering into the peak performance period. 


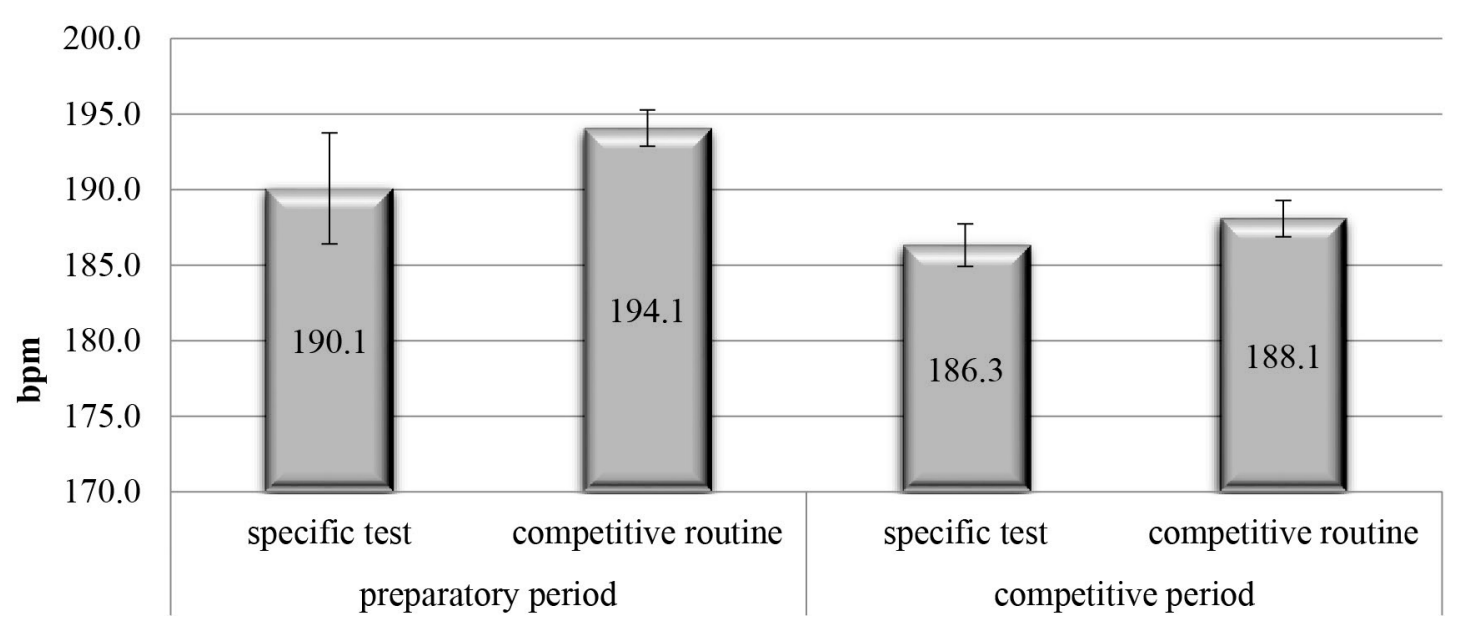

Figure 4. Heart rate values after specific test \& routine

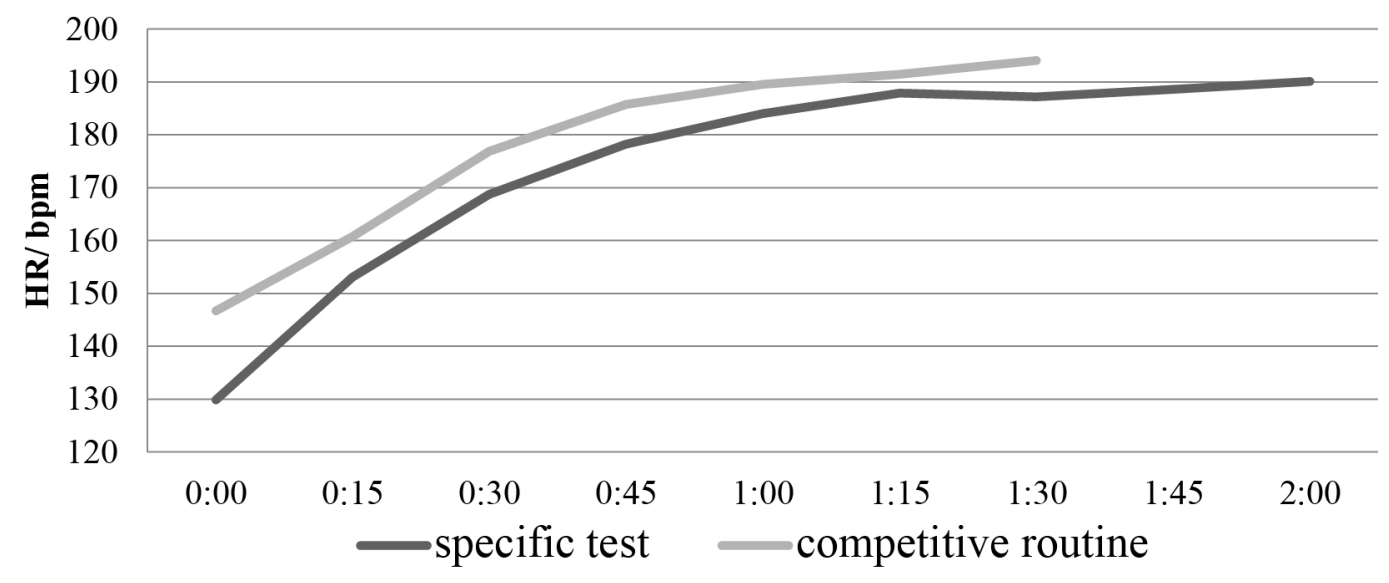

Figure 5. Heart rate values during specific test \& routine - preparation period

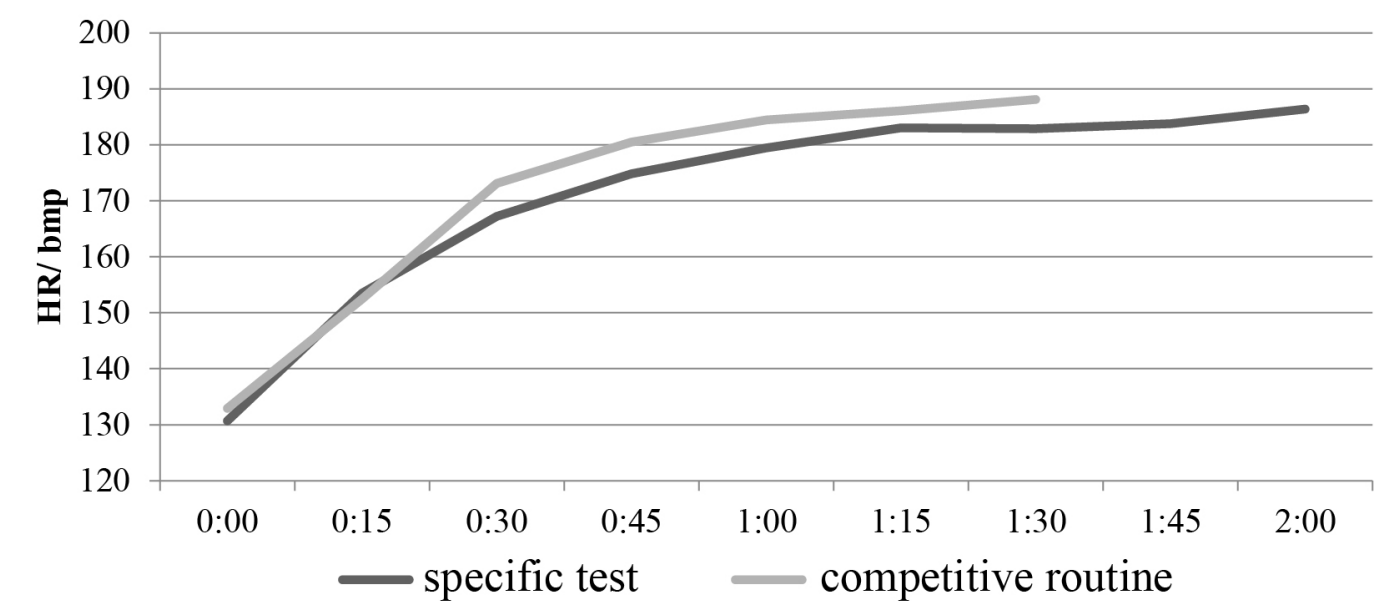

Figure 6. Heart rate values during specific test \& routine - competition period 
In figures $5 \& 6$ we can quite clearly see the cardio-dynamic and fast phases of the heart rate at the begginig of the tests. After the first $30 \mathrm{sec}$ of the load, values continued to rise slowly with just $20 \mathrm{~b} / \mathrm{min}$ up to the end of the tests. The specific endurance test provoked similar response in the cardio-vascular system but with lower values than the gymnastics routine. We have to keep in mind that the competitive routine is performed with apparatus in hands while the modified routine is free of apparatus, so the intensity of load in the upper body during the RG competitive routine is higher.

Table 2. Descriptive statistics of the HR and concentration of the blood lactate after the load

\begin{tabular}{|c|c|c|c|c|c|c|}
\hline Test & $\begin{array}{c}\text { HR } \\
\text { mean (SD) } \\
(\mathbf{b} / \mathrm{min}) \\
\end{array}$ & $\begin{array}{c}\text { HR } \\
\text { min. } \\
\text { (b/min) }\end{array}$ & $\begin{array}{c}\text { HR } \\
\text { max. } \\
\text { (b/min) }\end{array}$ & $\begin{array}{c}\text { La mean } \\
(\mathrm{SD}) \\
(\mathrm{mmol} / \mathrm{L})\end{array}$ & $\begin{array}{c}\text { La } \\
\text { min. } \\
(\mathrm{mmol} / \mathrm{L})\end{array}$ & $\begin{array}{c}\text { La } \\
\text { max. } \\
(\mathbf{m m o l} / \mathbf{L}) \\
\end{array}$ \\
\hline Modified routine PP & $190.1( \pm 5.4)$ & 182 & 200 & $7.2( \pm 2.5)$ & 4.6 & 11.5 \\
\hline $\begin{array}{l}\text { Gymnastics routine } \\
\text { PP }\end{array}$ & $194.1( \pm 4.2)$ & 187 & 200 & $8.7( \pm 2.3)$ & 5.7 & 12.8 \\
\hline Modified routine CP & $186.3( \pm 4.9)$ & 179 & 197 & $7.5( \pm 2.5)$ & 4.4 & 11.4 \\
\hline $\begin{array}{l}\text { Gymnastics routine } \\
\text { CP }\end{array}$ & $188.1( \pm 4.0)$ & 181 & 194 & $7.2( \pm 2.2)$ & 5.0 & 11.7 \\
\hline
\end{tabular}

$\mathrm{PP}$ - preparatory period; $\mathrm{CP}$ - competitive period

Table 3. Heart rate dynamics during the testing (means $\pm S D$ )

\begin{tabular}{ccccc}
\hline & \multicolumn{2}{c}{ Specific modified field test } & \multicolumn{2}{c}{ Gymnastics routine } \\
\hline $\mathbf{t}$ (min) & $\begin{array}{c}\text { Preparation } \\
\text { period }\end{array}$ & $\begin{array}{c}\text { Competitive } \\
\text { period }\end{array}$ & $\begin{array}{c}\text { Preparation } \\
\text { period }\end{array}$ & $\begin{array}{c}\text { Competitive } \\
\text { Period }\end{array}$ \\
\hline $\mathbf{0 0 : 0 0}$ & $129.8( \pm 17.1)$ & $130.7( \pm 13.6)$ & $146.7( \pm 10.9)$ & $132.9( \pm 17.6)$ \\
$\mathbf{0 0 : 1 5}$ & $153.1( \pm 15.6)$ & $153.5( \pm 9.1)$ & $160.8( \pm 11.6)$ & $152.5( \pm 10.7) *$ \\
$\mathbf{0 0 : 3 0}$ & $168.8( \pm 9.1)$ & $167.2( \pm 5.2)$ & $176.9( \pm 7.5)$ & $173.1( \pm 6.4)$ \\
$\mathbf{0 0 : 4 5}$ & $178.3( \pm 8.4)$ & $174.8( \pm 4.5) *$ & $185.8( \pm 5.3)$ & $180.5( \pm 5.3) *$ \\
$\mathbf{0 1 : 0 0}$ & $184.0( \pm 6.9)$ & $179.4( \pm 5.2) * *$ & $189.5( \pm 4.9)$ & $184.5( \pm 4.0) *$ \\
$\mathbf{0 1 : 1 5}$ & $187.9( \pm 6.0)$ & $183.0( \pm 5.1) * *$ & $191.5( \pm 4.2)$ & $186.1( \pm 4.1) *$ \\
$\mathbf{0 1 : 3 0}$ & $187.2( \pm 5.5)$ & $182.8( \pm 4.6) * *$ & $194.1( \pm 4.2)$ & $188.1( \pm 4.0) * *$ \\
$\mathbf{0 1 : 4 5}$ & $188.6( \pm 5.7)$ & $183.8( \pm 4.8) * *$ & & \\
$\mathbf{0 2 : 0 0}$ & $190.1( \pm 5.4)$ & $186.3( \pm 4.9) * *$ & & \\
\hline
\end{tabular}

${ }^{*} p<0.05$ significant difference between the periods

$* * p<0.01$ significant difference between the periods

\section{DISCUSSION}

We hope that not only the laboratory examination but also the field gymnastic "specific anaerobic" test provide valuable information about the actual level of anaerobic abilities of the gymnasts and their changes during training. Heller, et al. (1998) considers that the field test of 30-s repetitive jumping performance may be used as a simplified measure of anaerobic capacity, because of its close relationship to the standard laboratory $30 \mathrm{~s}$ Wingate test. Mackenzie, B. (2005) presents various field tests to determine the fitness level of the athletes (Harvard step test; Home step test; 3 min step test; ect.).

Gymnastics has been proven to be an anaerobic sport despite some discussions and different opinions. The duration of a rhythmic gymnast' routine is $90 \mathrm{sec}$ with high intensity of the execution. For that period approximately 90 to 100 different exercises are performed with body and apparatus with high 
level of difficulty (Petrova, 2015). Anaerobic lactic system is the main provider of energy for exercises lasting from 10 to $60 \mathrm{sec}$ and the aerobic system requires 60 to $80 \mathrm{sec}$ to start producing energy (Bompa, Buzzicheli, 2015). There is an increasing contribution of the anaerobic metabolism in gymnastics (Jemni et al., 2011). The training sessions in rhythmic gymnastics are in aerobic regime of work (Gateva, 2008) but the competitive programs (routines) which are repeated many times per training session have submaximal demand based on the tested indicators. The aerobic fitness a gymnast may possess will show how quickly gymnasts recover between high intensity load such as routines or part of the routines. The blood lactate shows the anaerobic involvement of the body systems into the measured physical loads. Although there is no significant difference between the tests and periods, in the preparatory period the concentration of blood lactate is slightly lower in the specific test $(7.4 \mathrm{mmol} / \mathrm{l})$ than in the routine $(8.4 \mathrm{mmol} / \mathrm{l})$ but in the competitive period it is decreased in the value of the routine and we have recorded similar value for the specific test. By rehearsing the same skills and routines the gymnast becomes increasingly "economical" (Jemni et al., 2011) - in this case the competitive routine was practised many times per day in comparison with the specific endurance test which was not performed at all. Despite all the contradictive opinions about the reliability of the heart rate, some authors consider it as a useful first approach to assess exercise intensity in technical-combinatory sports such as gymnastics (Marina, Rodríguez, 2014). For others, heart rate is a significant variable used to explain performance in gymnastics (Douda et al., 2008). The results from the heart rate show that we have a certain type of a plateau - from the $45^{\text {th }} \mathrm{sec}$ of the loads onwards.
Analysing the curve of the heart rate we considered that from this moment the aerobic mechanism started to be the supplier of energy for the remaining part of the routine. Although the values of the heart rate were lower with 3 to $5 \mathrm{bpm}$ for the specific endurance test (the routine still showed higher demands on the gymnasts' body systems) we consider our attempt to measure the sport-specific physical abilities (specific endurance) a successful one. The two curves of the heart rate response towards the physical load are identical. The test is applicable as it is standardized and with the predetermined exercises all gymnasts will have the same physical load and we can compare the athletes to one another. As the test was set by a certain tempo we still can talk about specific endurance in rhythmic gymnastics. If we ask the gymnasts to perform it with maximal speed, then it can be an anaerobic endurance. The presented test is informative and gives the opportunity to compare the result from previous testing or to compare the specific endurance between different gymnasts. It is expected that with appropriate training between each test, the analysis would indicate an improvement.

Further research is needed to continue the process of establishing the various types of reliability and validity of the test.

\section{CONCLUSIONS}

The suggested test is a standard field test suitable for active, mid to high level rhythmic gymnasts aged above 12 years which can measure the current specific endurance of a gymnast and compare it with her previous testing. It can also be used to compare the specific endurance between different rhythmic gymnasts. Further investigation is needed to determine the correlation between the proposed test and the sports achievement. The blood lactate is the best indicator for the an- 
aerobic regime of work of the physical activities in the study. The test can also be applied with several applications - to develop the anaerobic power (endurance) when requested to perform at maximal speed; to develop the aerobic endurance when performed with normal tempo ( $84 \mathrm{bpm})$ with several repetitions without resting period.

\section{ACKNOWLEDGEMENTS}

Supported by Grant (contract № 373/13.06.2012) from the National Sports Academy and Ministry of Education (Bulgaria).

\section{REFERENCES}

Alves, C., Borelli, M., Paineli, V., Azevedo, R., Borelli, C., Lancha Junior, A., Gualano, B., Artioli, G. (2015). Development of a Specific Anaerobic Field Test for Aerobic Gymnastics. PLoS One, DOI:10.1371/Journal. pone.0123115 April 13, 2015.

Batista, A., Gomes Natacha, Garganta R., Avila-Carvalho, L., (2018). Training intensity of group in rhythmic gymnastics. Science, movement and health, Vol. XVIII, Issue 1, 18 (1): 17-24.

Bompa, T., Buzzicheli, C. (2015). Periodization of sport training, Human Kinetics, Champaign, IL.

Douda, H., Toubekis, A., Avloniti, A., Tokmakidis, S. (2008). Physiological and Anhtropometric Determinants of Rhythmic Gymnastics Performance. International Journal of Sports Physiology and Performance, Human Kinetics, Inc. Vol. 3, pp. 41-54.

Gateva, M. (2008). Examination of the training loading in rhythmic gymnastics and perfecting the training methods. Doctoral dissertation. National Sports Academy, Sofia.

Gateva, M. (2014). Investigation of the effect of the training load on the athletes in rhythmic and aesthetic group gymnastics during the preparation period. Research in Kine- siology, Vol. 4, pp. 40-44.

Gateva, M. (2015). Test to determinate the fitness level in rhythmic gymnastics. Sport Mont, XIII (43-44-45), pp. 63-69.

Guidetti L, Baldari C, Capranica L, Persichini C, Figura F. Energy cost and energy source of ball routine in rhythmic gymnasts. Int J Sports Med. 2000; Vol. 21, pp. 205-209.

Jemni, M., Sands, W., Salmela, J., Holvoet. P., Gateva, M. (2011). The Science of Gymnastics, Routledge, Oxon.

Fernández-Villarino, M., Hernaiz-Sánchez, A., Sierra-Palmeiro, E., Bobo-Arce, M. (2018). Performance indicators in individual rhythmic gymnastics: correlations in competition, Journal of Human Sport and Exercise, 13(3), pp. 487-493.

Heller, J., Tûma, Z., Dlouhá, R., Bunc, V. and Nováková, N. (1998). Anaerobic capacity in elite male and female gymnasts. Acta Universitatis Carolinae - Kinanthropologica, Vol. 34, 2.

Mackenzie, B. (2005). 101 Performance Evaluation Tests. Electric Word plc, London.

Manos, M., Grigore, V., Popescu, L. (2012). Study about the energy expenditure assessment in rhythmic gymnastics. Science, movement and health, Vol. XII, No. 2.

Marina, M., Rodríguez, F. (2014). Physiological demands of young women's competitive gymnastic routines, Biology of Sport, Vol. 31 No3, pp. 217-222.

Polat, S., Günay, M. (2016). Comparison of Eight Weeks Rhythmic Gymnastics, Pilates and Combined Training in Terms of Some Physical, Physiological and Motoric Parameters, International Journal of Human Movement and Sports Sciences, Vol. 4 No. 4, pp. 61-69.

Sleeper, M., Kenyon, 1., Casey, E. (2012). Measuring fitness in female gymnasts: the Gymnastics functional measurement tool. The international journal of sports physical thera- 
py, Vol. 7, No. 2, pp. 124-138.

Nikolov, V., Karelieva, D. (2004). Planirane na trenirovachnotot natovarvane, III mejdynaroden naychen kongres Sport, Stres, Adaptatsia, Sofia.//Николов, В., Кателиева, Д. (2004). Планиране на тренировъчното натоварване, III-ти международен научен конгрес Спорт, Стрес, Адаптация, София.

Petrova, M. (2015). Dinamika na treniro- vachnoto natovarvane na natsionalnia otbor po hydojestvena gimnastika jeni - individyalno za 2011 i za 2014 g., Sofia, NSA, DR. // Петрова, M. (2015). Динамика на тренировъчното натоварване на националният отбор по художествена гимнастика жени - индивидуално за 2011 год. и за 2014 год. София, НСА, ДР.

Corresponding author:

Maria Gateva

Department of Gymnastics National Sports Academy „Vassil Levski” Studentski grad, 21, Acad. Stefan Mladenov str. Sofia 1700, Bulgaria E-mail: maria.gateva@abv.bg 